\title{
Correspondence
}

\section{Rapid tracheal intubation - atracurium may not be the answer}

To the Editor:

We read the recent article on rapid tracheal intubation using atracurium by Naguib et al.' with considerable interest and some concern.

The use of a nondepolarizing relaxant to facilitate rapid tracheal intubation during a rapid sequence induction for patients with a full stomach is indicated in certain conditions, for example, the patient with an open cye injury. Excellent intubating conditions are essential to minimize effects on intraocular pressure. Although the authors state that they were able to intubate the patients within one minute after administration of the full relaxant dose with optimal priming, excellent intubating conditions were obtained in only five of 22 patients. This suggests that even with priming, atracurium may not be an appropriate choice for rapid tracheal intubation, particularly in the patient with an open eye injury.

The apparent discrepancy between complete twitch suppression and failure to obtain excellent intubating conditions in this study may be attributed to three factors: (I) the use of a twitch frequency of $1 \mathrm{~Hz}$ may overestimate the degree of neuromuscular blockade (while VibyMogensen ${ }^{2}$ does state that this frequency is useful in the clinical setting, fatigue of the neuromuscular junction may occur at frequencies greater than $0.15 \mathrm{~Hz}),{ }^{3,4}(2)$ the diaphragm is less sensitive to neuromuscular blockade than the peripheral neuromuscular junctions, ${ }^{5,6}$ and (3) the use of surface electrodes may cause overestimation of the degree of blockade?

Another concern relates to the priming principle itself. Although the priming principle has generated a flurry of enthusiasm, it may increase the risk at operation. Musich and Walts recently reported a case in which pulmonary aspiration occurred after a priming dose of vecuronium, ${ }^{8}$ suggesting that priming doses should be administered with discretion.

Naguib et al. concluded that "this [atracurium] may" provide an alternative to succinylcholine for rapid endo tracheal intubation." However, "rapid (endo)tracheal intubation" refers specifically to a rapid sequence induction in patients with full stomachs - most in emergency situations. Because of the arguments discussed above, we cannot endorse atracurium as an altemative to succinylcholine for patients requiring rapid sequence inductions. We believe that pancuronium remains the nondepolarizing muscle relaxant of choice for patients with open eye injuries requiring a rapid sequence induction. ${ }^{9}$

M. E. McLeod MD FRCPC

J. Lerman MD FRCPC

Department of Anaesthesia

The Hospital for Sick Children

555 University Avenue

Toronto Ontario

M5G IX8

\section{REFERENCES}

I Naguib M, Gyasi HK, Abdulatif M, Absood GH. Rapid tracheal intubation with atracurium - a comparison of priming intervals. Can Anaesth Soc J 1986, 33: 150-6.

2 Viby-Mogensen J. Clinical measurement of neuramuscular function: an update. Clinies in Anesthesiology 1985; 3: 467-82.

3 Ali $H H$, Savarese $J J$. Stimulus frequency and doseresponse curve to d-tubocurarine in man. Anesthesiology 1980; 52: 36-9.

4 Tran DQ, Amaki Y, Oha Y, Nagashima H, Duncalf D, Foldes $F F$. Simultancous in vivo measurement of $N M$ block on three muscles. Anesthesiology 1982; 57: A.276.

6 Donati F, Antzaka $C$, Bevan DR. Potency of pancuronium at the diaphragm and the adductor pollicis muscle in humans. Anesthesiology 1986; 65: 1-5.

7 Stiffel $P$. Hameroff $S R$, Blitt $C D$ et al. Variability in assessment of ncuromuscular blockade. Anesthesiology 1980; 52: 436-7.

8 Musich J, Walts LF. Pulmonary aspiration after a priming dose of vecuronium. Anesthesiology 1986; 64: 517-9.

9 Lerman J, Kiskis AA. Lidocaine attenuates the intraocular pressure response to rapid intubation in children. Can Anaesth Soc J 1985, 32: 339-45.

10 Brown EM, Krishraprasad D. Smiler BG. Pancuronjum for rapid induction technique for tracheal intubation. Can Anaesth Soc J 1979, 26: 489-91.

\section{REPLY}

Thank you for giving me the opportunity to reply to the ietter of Drs. Mcleod and Lerman.

In our paper ${ }^{\prime}$ we did not suggest or recommend using the priming lechnique with atracurium in patients with open eye injury or in patients undergoing emergency surgical proce dures. We also noted that even with priming, ${ }^{1.2}$ intubations 
may not be quite as ideal as they usually are after succinylcholine. We clearly stated in another report' ihat "The use of priming doses in this study, as in the others reported", did not provide ideal intubating conditions." Conditions for intubation depend on both depth of anaesthesia and depth of paralysis. Although we were able to improve the intubating conditions following priming with atracurium by additional doses of thiopentone, administered before intubation, ${ }^{3}$ we believe that further studies are warranted in order to establish the safety and the efficacy of the priming principle in emergency situations.

Non-depolarizing muscle relaxants have different effects on different muscie groups. The diaphragm is more resistam to the effects of non-depolarizing muscle relaxants than other muscles. ${ }^{45}$ Using train-of-four stimulation, Donati et al.$^{6}$ demonstrated in humans a more than two-fold difference between the diaphragm and the adductor pollicis with respect to their sensitivity to pancuronium. The implication is that measuring the onset of diaphragmatic paralysis can yield a better correla. tion with the insubating conditions. However, until diaphragmatic paralysis can be routinely monitored clinically, the use of the adductor pollicis will be the standard method of montoring neuromuscular function. In addition. Capan et al. ${ }^{7}$ found no significant difference in twitch height suppression and peak current amplisude when a constant current stimulator was used with either surface or needle electrodes.

The priming manoeuvre is best viewed as a new application of an old practice - the pretreament with small doses of non-depolarizing muscle relaxant prior to the administration of succinylcholine. The use of the priming technique has been widely evaluated in patient populations by different authors, with no risk to the patient. The case reported by Musich and Walts ${ }^{7}$ did not convince us that the pulmonary aspiration occurred because of the priming technique. Their patient weighed $102 \mathrm{~kg}$ and had consumed an unknown quantity of alcotol one hour before an automobile accident and was premedicated with meperidine $100 \mathrm{mg}$ and hydroxyzine $50 \mathrm{mg}$ IM one hour before surgery. This patient was at a higher risk for pulmonary aspiration because of the above-mentioned factors and we believe that it is unjustifiable to indicate that the aspirasion occurred because of the priming dose of vencuronium, without mentioning the other contriburing factors.

McLeod and Lerman in their letter stated that "Pancuronium ... remains the non-depotarizing muscle relaxant of choice for patients requiring a rapid sequence induction when a nondepolarizing relaxant is indicated." The studies 9,10 quoted by them did not include either comparisons with other nondepolarizing muscle relaxanis or observations in patients scheduled for emergency surgical procedures. Therefore, calltion should be exercised when extrapolating these results to emergency situations. In addition, a relatively larger dose of pancuronium $\left(0.15 \mathrm{mg} \cdot \mathrm{kg}^{-1}\right)$ was recommended in these studies to facilitate rapid tracheal intubation. High-dose pancuronium $0.15 \mathrm{mg} \cdot \mathrm{kg}^{-1}$ (or other long-duration, non-depolarizing relax. ants; produces a prolonged paralysis with accentuated autonomic side effects. ${ }^{10}$ This concern was addressed in our paper.' Using equipotent doses of atracurium $\left(330 \mu \mathrm{g}^{\cdot} \mathrm{kg}^{-1}\right)$, vecuronium (66 $\mu \mathrm{g} \cdot \mathrm{kg}^{-1}$ ) or pancuronium (75 $\mu \mathrm{g} \cdot \mathrm{kg}^{-1}$ ), Gramstad et al." reported that the mean times to 95 per cent witch depression were: atracurium $2.7 \mathrm{~min}$, vecuronium $2.8 \mathrm{~min}$ and pancuronium $3.6 \mathrm{~min}$. Furshermore, Schiller and Feldman ${ }^{2}$ demonstrated thas atracurium $\left.10.6 \mathrm{mg} \cdot \mathrm{kg}^{-1}\right)$, resulted in a statistically significant earlier onses of satisfactory intubating conditions than with vecuronium $\left(0.1 \mathrm{mg} \cdot \mathrm{kg}^{-1}\right.$ ) or pancuronium $\left(0.1 \mathrm{mg} \cdot \mathrm{kg}^{-1}\right)$.

The onset of neuramuscular paralysis produced by any non-depolarizing muscle relaxamt can be accelerated by the administration of larger doses. ${ }^{13,14}$ Therefore, we do nor agree with McLeod and Lerman that pancuronium is the muscle relaxam of choice for patients requiring a rapid sequence induction when succinylcholine is considered undesirable or contraindicated. We believe that because of its more rapid onset and shorter duration of action and fewer side effects, atracurium (or vecuronium) with or without priming is a better choice.

Since, as yet. the proposed ideal muscle relaxam is not available, studies on the priming principle might provide an alternative, and this may be the answer!

Mohamed Naguib MB B CH M SC FFARCS1

Department of Anesthesiology

King Faisal University

King Fahd Hospital

P.D. Box 2208

Al Khobar 31952

Saudi Arabia

\section{REFERENCES}

1 Nagaib $M$, Gyasi $H K$, Abdulatif $M$, Absood $G H$. Rapid tracheal intubation with atracurium - a comparison of priming intervals. Can Anaesth Soc J 1986; 33: 150-6.

2 Naguib M, Abdulatif $M$, Absood $G H$. The optimal priming dose for atracurium. Can Anaesth Soc J 1986; 33: 453-7.

3 Naguib M, Abdularif M, Gyasi HK, Absood GH. Priming with atracurium: improving intubating conditions with additional doses of thiopental. Anesth Analg 1986; 65: 1295-9.

4 Foldes FF, Monte AP, Brunn HM, Wolfson B. Studies with muscle relaxants in unanesthetized subjects. Anesthesiology 1961; 22: 230-6.

5 Tran DQ, Amaki Y, Ohta Y, Nagashima $H$, Duncalf D, Foldes $F F$. Simultaneous in vivo measurement of NM block on three muscles (Abstract). Anesthesiology 1982; 57: A276.

6 Donati F, Anzaka $C$, Bevan DR. The diaphragm and adductor pollicis dose-response cures for pancuronium (Abstract). Anesthesiology 1985; 63: A322.

7 Capan LM, Satyanarayana $T$, Patel KP er al. Assessment of neuromuscular blockade with surface electrodes (Abstract) Anesth Analg 1981; 60: 244-5

8 Musich J, Walts LF. Pulmonary aspiration after a priming dose of vecuronium. Anesthesiology 1986; 64: 517-9.

9 Cunliffe $M$, Lucero VM, McLeod ME, Burrows FA, Ler mon $J$. Ncuromuscular blockadc for rapid tracheal intubation in children: comparison of succinylcholinc and pancuronium. Can Anaesth Soc J 1986; 33: 760-4.

10 Brown EM, Krishmaprasad D, Smiler BG. Pancuronium for rapid induction technique for tracheal incubation. Can Anaesth Soc J 1979; 26: 489-91.

11 Gramstad $L$, Lilleaasen $P$, Minsaas $B$. Onset time and duration of action for atracurium, ORG NC 45 and pancuronium. Br J Anaesth 1982; 54: 827-9.

12 Schiller DJ, Feldman SA. Comparison of intubating conditions with atracurium, vecuronium and pancuronium. Anaesthesia 1984; 39: 1188-91.

13. Scott RPF, Savarese JI, Basta SJ et al. Clinical pharmacology of atracurium in high dose. Br J Anaesth 1986; 58: 834-8.

14 Lennon RL, Olson RA, Gronert GA, Atracurium or vecuronium for rapid sequence endotracheal intubation. Anesthesiology 1986; 64: 510-3 